\title{
Tendance de marché en France sur la présence des protéines végétales dans les produits alimentaires
}

\author{
Morgane Estève-Saillard ${ }^{\star}$ \\ GEPV, Groupe d'Étude et de Promotion des Protéines Végétales, 66 rue la Boétie, 75008 Paris, France
}

Reçu le 25 mars 2016 - Accepté le 6 avril 2016

\begin{abstract}
Résumé - Le contexte actuel est favorable à l'utilisation croissante des protéines végétales dans les produits alimentaires : préoccupations sanitaires et environnementales, développement du flexitarisme et dans une moindre mesure du végétarisme, inscriptions des protéines végétales dans les secteurs de recherche stratégiques pour la France... Le bilan de référencement du GEPV, Groupe d'Étude et de Promotion des Protéines Végétales, fait le point tous les deux ans sur la présence des protéines végétales dans les produits alimentaires commercialisés en France. Les résultats du dernier bilan montrent la nette progression de l'utilisation de protéines végétales dans tous les rayons alimentaires, en progression constante depuis plusieurs années. Le blé reste la source largement majoritaire, suivi par le soja. Des spécificités se dégagent dans l'utilisation des ingrédients protéiques végétaux; par exemple les protéines de pois et de soja sont principalement utilisées pour les produits carnés alors que le gluten et la féverole sont surtout utilisés pour les produits de panification. De nouvelles utilisations des sources protéiques voient également le jour et feront l'objet d'un suivi du GEPV, comme les microalgues ou les mycoprotéines.
\end{abstract}

Mots clés : Protéines végétales / référencement / lupin / pois / soja / féverole / gluten

\begin{abstract}
Market trend in France on the presence of plant proteins in food products. The current context is propitious to the development of plant proteins use for food: health and environmental considerations, expansion of flexitarism and to a lesser extent of vegetarianism, addition of research on plant proteins to the strategic research agenda in France... GEPV, French association for the promotion of plant protein in foods, reiterated an analysis referencing in France the plant proteins in food products. It shows a significant and continuous increase of the use of plant proteins in each type of food sections, for many years now. Wheat remains the first source of plant protein used, followed by soybean proteins. Specific uses of plant proteins appear in different food categories: for instance soy and pea proteins are mainly used for meat based products, whereas wheat and fava bean are especially present in bakery wares. New protein sources are emerging and will be also monitored by GEPV, as microalgae and mycoproteins.
\end{abstract}

Keywords: Plant protein / referencing / lupin / pea / soybean / faba bean / gluten

Le secteur des ingrédients protéiques végétaux connaît un essor significatif depuis plusieurs années, et représente un marché en pleine croissance. Le marché mondial des protéines végétales représentait 6,9 milliards d'euros en 2013, et devrait atteindre 9,8 milliards d'euros en 2018, soit une croissance de $42 \%$ (Nutrimarketing, 2014). Ce marché est porté par une demande mondiale annuelle croissante en protéines végétales qui devrait induire une hausse de $40 \%$ d'ici à 2030 (BIPE, 2014). On parle de transition protéique : suite à une $1^{\mathrm{e}}$ phase d'augmentation de la demande mondiale en protéines animales et végétales due à l'augmentation du niveau de vie, on observe

\footnotetext{
^ Correspondance : m.saillard@66laboetie.fr
}

dans certains pays une $2^{\mathrm{e}}$ phase de substitution partielle de la part des protéines animales au profit des protéines végétales, pour des raisons sociétales principalement (préoccupations de santé, environnementales,...).

Afin de suivre cette tendance et de l'évaluer, le GEPV réalise tous les deux ans un bilan de référencement qui recense, via les étiquetages des produits alimentaires en magasin, les produits contenant des protéines végétales. Ce recensement se fait par visite dans les magasins situés dans la région de Clermont-Ferrand. Des comparaisons ont eu lieu avec les éditions précédentes avec d'autres régions, où la même progression a été observée. 


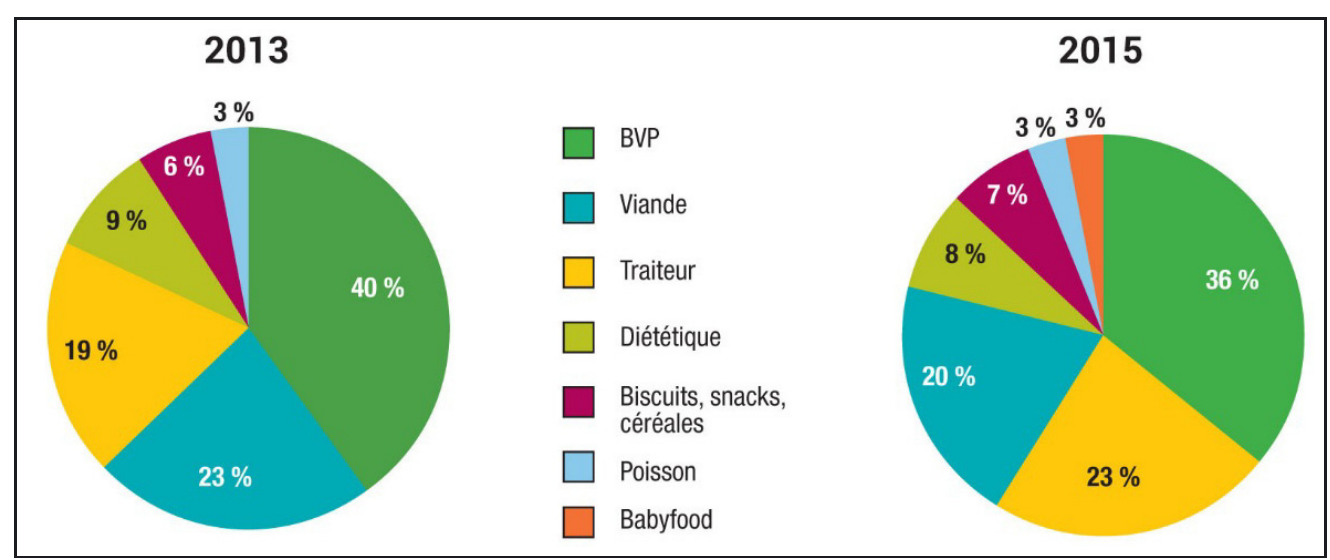

Fig. 1. Répartition de l'utilisation des protéines végétales dans les différentes rayons en 2013 et 2015. Source : Bilan de référencement GEPV 2015.

Les résultats du dernier bilan de référencement, datant de 2015, montrent une progression de la présence de protéines végétales dans tous les rayons alimentaires étudiés.

\section{Méthodologie}

L'enquête est effectuée auprès d'une vingtaine de magasins de la région de Clermont-Ferrand, si possible les mêmes tous les 2 ans. À titre d'exemple, entre 2013 et 2015 seul un magasin était différent.

Différents types de magasins sont visités (grandes et moyennes surfaces, magasins spécialisés, de proximité, et hard discount), pour avoir une vision large à défaut d'être exhaustive, sur l'offre disponible sur le marché français.

Six segments de produits sont étudiés :

- la boulangerie-viennoiserie-pâtisserie (BVP);

- les biscuits, snacks et céréales (apéritifs, barres céréalières, biscuits,...);

- les charcuteries et préparations à base de viandes ;

- le rayon traiteur (quiches, croques, sandwichs, plats cuisinés, soupes...);

- les préparations à base de poissons ;

- le rayon diététique;

- et enfin, le rayon de l'alimentation infantile, dit «baby-food».

L'enquêteur recherche sur les listes d'ingrédients des produits la mention des protéines végétales : «farine de lupin», «gluten de blé », « protéine de soja »,...

Les mentions suivantes ne sont pas prises en compte : hydrolysats de protéines végétales, graines de soja, fibres végétales, lécithine de soja. Les produits au tofu ne sont pas non plus intégrés à l'étude.

Chaque article relevé compte pour 1 dans la base de données constituée. Les références différentes mais de même marque sont toutes comptabilisées, pour que l'étude soit plus représentative du marché et du nombre de variantes produits réellement présentes en rayon.

\section{Résultats}

\subsection{Une hausse dans toutes les catégories de produits}

Le bilan 2015 a montré une progression générale de $+18 \%$ du nombre de produits alimentaires contenant des protéines végétales. Cette tendance est confirmée depuis 2009.

On observe une certaine stabilité avec les années précédentes dans la part des différents segments de produits étudiés. Les rayons contenant le plus de produits avec protéines végétales sont la BVP, le rayon traiteur et les produits à base de viande, qui représentent à eux trois près de $80 \%$ des produits référencés contenant des protéines végétales (Fig. 1). La BVP représente à elle seule $36 \%$, ce qui s'explique par la nature même des produits de panification.

Le rayon traiteur connait la plus forte hausse, avec une augmentation du nombre de produits contenant des protéines végétales de $46 \%$ entre 2013 et 2015 .

Le rayon Biscuits, snacks, céréales est lui aussi en progression de $+43 \%$.

Les rayons Préparations à base de viande et Diététiques restent relativement stables (hausse de 1 à $2 \%$ ).

\subsection{Le blé et le soja majoritaires}

Cinq sources de protéines ont été enregistrées dans le bilan de référencement : fève (farine), lupin (farine, protéine), blé (gluten, protéine, protéine texturée), pois (farine, protéine) et soja (farine, protéine, texturés). Il peut y avoir des associations entre ces différentes protéines dans un même produit.

Pour deux tiers des produits, la source de protéine végétale utilisée est le blé. Il est suivi par le soja qui représente $17 \%$ des utilisations de protéines végétales, et par des associations $(10 \%)$, notamment «farine de fève et gluten » dans les produits de BVP, «protéines de soja et gluten » dans les produits diététiques (Fig. 2).

Au niveau mondial, le soja reste la source d'ingrédient protéique végétal majoritaire, avec les isolats, concentrats et protéines texturées qui représentent $56 \%$ du marché en volume en 2014 (Nutrimarketing, 2014). 


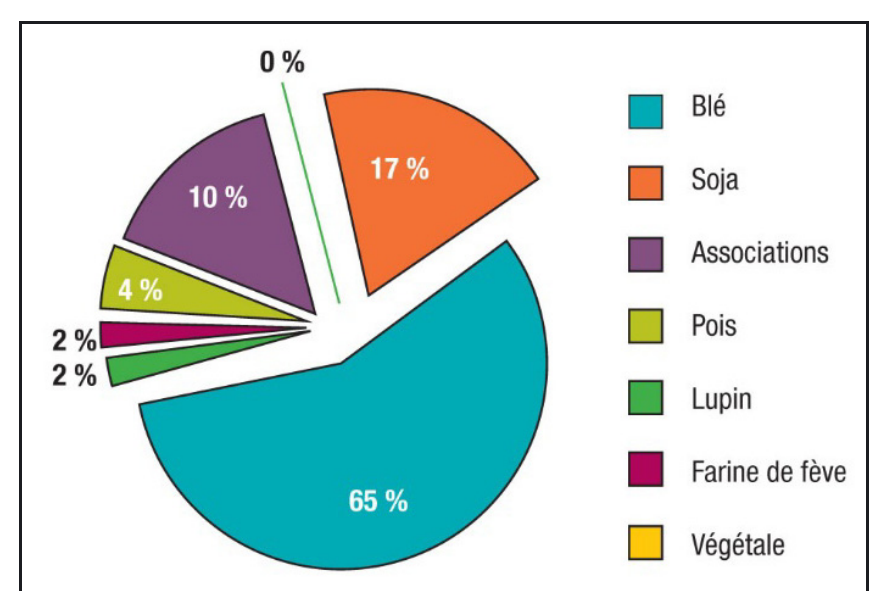

Fig. 2. Part des différentes sources de protéines végétales dans les 5098 produits référencés en 2015. Source : Bilan de référencement GEPV 2015.

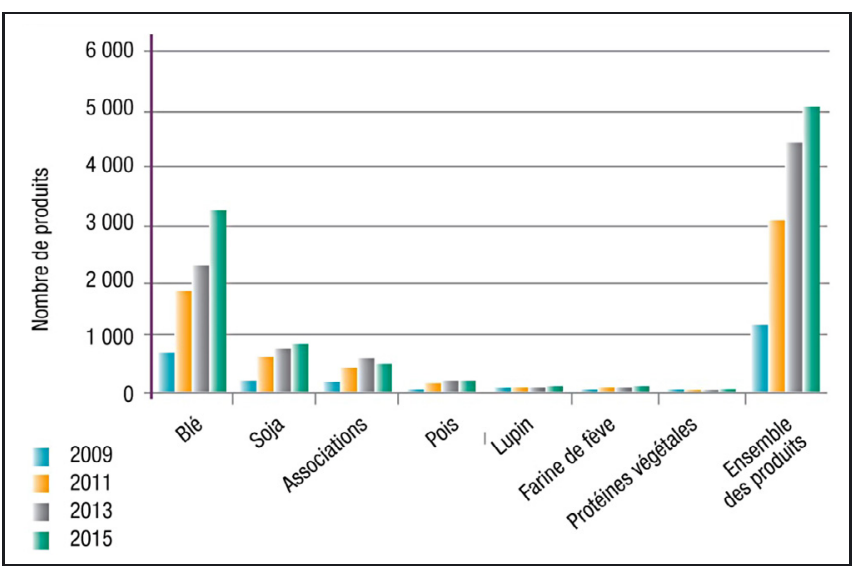

Fig. 3. Évolution du nombre de produits référencés par source de protéines végétales. Source : Bilan de référencement GEPV 2015.

En France presque toutes les sources de protéines connaissent une croissance d'utilisation dans les produits, avec une hausse plus marquée pour le blé : $+10 \%$ pour le gluten par rapport à 2013 (Fig. 3).

\subsection{Des spécificités d'utilisations}

On note certaines spécificités d'utilisations, déjà relevées lors des précédentes enquêtes : le blé est très largement utilisé en BVP, alors que le soja et le pois se retrouvent principalement dans les préparations à base de viandes; la fèverole est principalement utilisée en BVP et dans les produits traiteur, et le lupin se répartit entre la BVP, les biscuits et les produits diététiques (Fig. 4).

\subsection{De nouvelles sources à développer}

On observe depuis quelques années l'apparition de nouvelles sources de protéines végétales, comme les microalgues ou les mycoprotéines.
Si elles sont également utilisées pour la production de lipides, les microalgues peuvent avoir une teneur significative en protéines, par exemple les chlorelles ou les spirulines qui sont les deux microalgues actuellement utilisées comme source de protéines pour l'alimentation humaine ou animale. En France, la culture de microalgues a débuté dans les années 1970 principalement pour une utilisation en aquaculture. Des développements ont ensuite débuté pour la production de pigments (bêta-carotène et astaxanthine) puis vers la production de lipides (DHA, ARA, EPA) et de farines riches en protéines.

Les produits à base de mycoprotéines sont peu présents en France, et sont surtout commercialisés au Royaume-Uni. Par exemple la marque Quorn ${ }^{\mathrm{TM}}$ commercialise des substituts de viande à base de mycoprotéines, qui reproduisent l'apparence, la texture et le goût de la viande. On trouve ainsi des saucisses, steaks hachés, panés, ... accessibles aux végétariens.

Les sources de protéines végétales sont nombreuses, on peut donc potentiellement les extraire de tous les produits végétaux pour peu qu'ils en contiennent une quantité suffisante. Cependant il faut prendre en compte les verrous technologiques (par exemple les techniques d'extraction disponibles) et économiques (viabilité du marché et débouchés). Par exemple, de nombreux travaux sont actuellement menés sur la valorisation possible de la protéine de colza.

\section{Conclusions : une tendance en hausse soutenue par une image positive du consommateur}

Le potentiel de développement des protéines végétales, en France comme au niveau mondial, n'est plus à démontrer. Les résultats du bilan de référencement du GEPV le prouvent : les protéines végétales sont de plus en plus utilisées dans les produits alimentaires.

La montée du végétarisme et du flexitarisme en France et en Europe alimente la tendance à incorporer plus de protéines végétales dans les produits. Celles-ci ont bonne presse auprès de tous les consommateurs, puisqu'ils sont $93 \%$ en France à penser qu'elles sont bonnes pour la santé, $85 \%$ indispensables à tous et $78 \%$ bonnes pour l'environnement (GEPV/CSA, 2014).

Avec une image positive (bonnes pour la santé, écorespectueuses, qualitatives, etc.) et des leviers d'achat porteurs (raisons nutritionnelles avec réduction du taux de matières grasses par exemple), les protéines végétales connaissent une perspective de consommation à la hausse.

Il est toutefois nécessaire de poursuivre l'éducation du consommateur, pour lui expliquer ce que sont les protéines végétales, dans quelles denrées elles se trouvent et l'intérêt qu'elles peuvent présenter.

Cette tendance ne doit pas venir en opposition à la consommation de viande, mais plutôt souligner la complémentarité nécessaire de ces deux sources de protéines. 


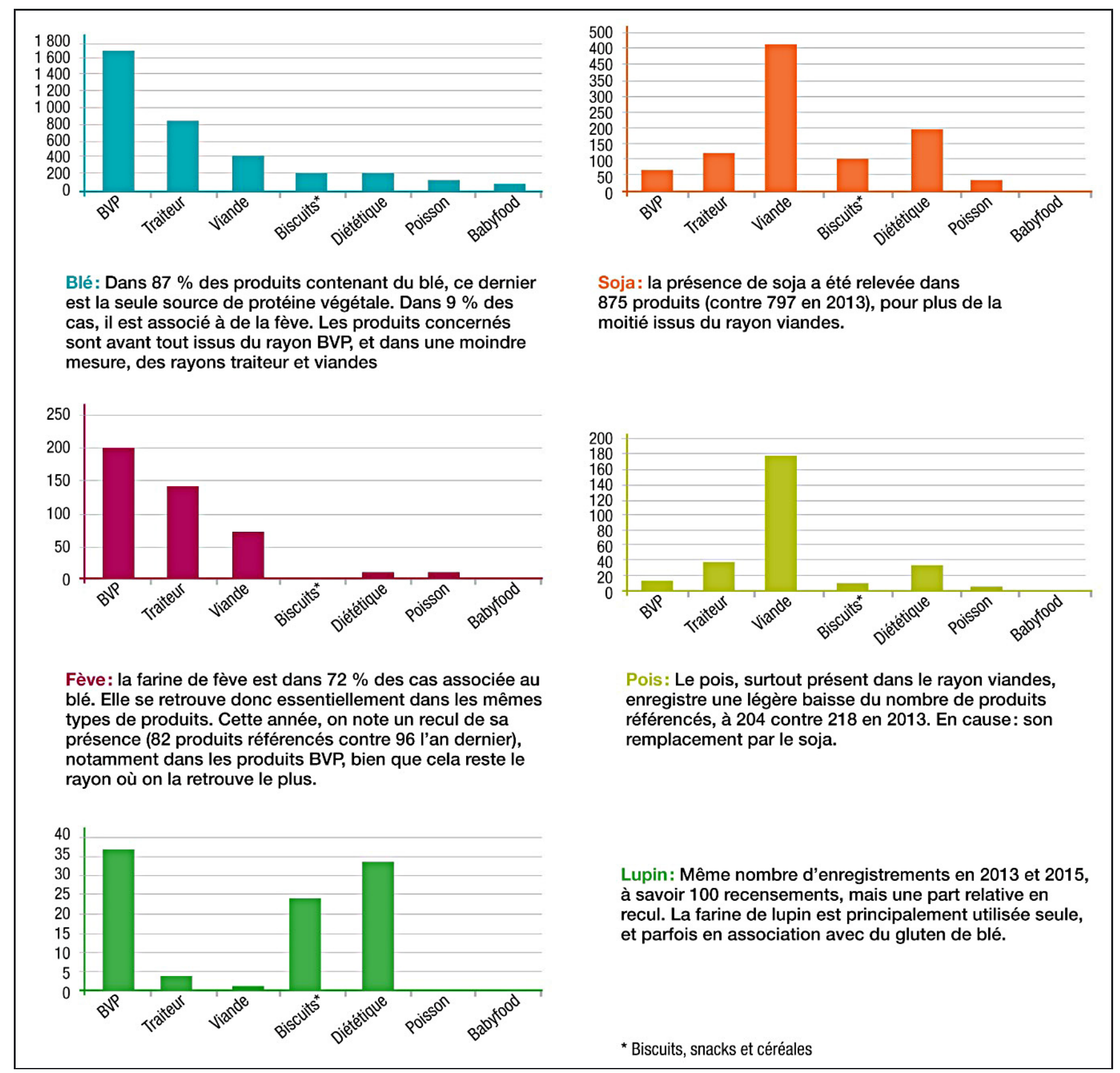

Fig. 4. Spécificités d'utilisation par source de protéines végétales. Source : Bilan de référencement GEPV 2015.

\section{Références}

BIPE pour Sofiprotéol. 2014. La filière des oléoprotéagineux pour répondre aux enjeux globaux à horizon 2030.

Gehin C. 2015. Bilan de référencement GEPV en France.

Étude GEPV/CSA. 2014. La perception des protéines végétales.
Nutrimarketing. 2014. Protéines - Consommations, marché et solutions innovantes.

GEPV. Lettre Positions $n^{\circ} 59$ octobre 2015. Disponible sur : www.gepv.asso.fr/fichiers/20151028140511_GEPV_Lettre_ Positions_n59_octobre_2015.pdf.

Cite this article as: Morgane Estève-Saillard. Tendance de marché en France sur la présence des protéines végétales dans les produits alimentaires. OCL 2016, 23(4) D403. 